\title{
Unplanned index hospital admissions among new older high-cost health care users in Ontario: a population-based matched cohort study
}

\author{
Sergei Muratov MD PhD, Justin Lee ACPR MD, Anne Holbrook MD MSc, J. Michael Paterson MSc, \\ Jason R. Guertin PhD, Lawrence Mbuagbaw MD PhD, Tara Gomes PhD, Wayne Khuu MPH, \\ Priscila Pequeno MSc, Jean-Eric Tarride PhD
}

Abstract

Background: Most health care spending is concentrated within a small group of high-cost health care users. To inform health policies, we examined the characteristics of index hospital admissions and their predictors among incident older high-cost users compared to older non-high-cost users in Ontario.

Methods: Using Ontario administrative data, we identified incident high-cost users aged 66 years or more and matched them 1:3 on age, gender and Local Health Integration Network with non-high-cost users aged 66 years or more. We defined high-cost users as patients within the top $5 \%$ most costly high-cost users during fiscal year 2013/14 but not during 2012/13. An index hospital admission, the main outcome, was defined as the first unplanned hospital admission during 2013/14, with no hospital admissions in the preceding 12 months. Descriptively, we analyzed the attributes of index hospital admissions, including costs. We identified predictors of index hospital admissions using stratified logistic regression.

Results: Over half (95 375/175 847 [54.2\%]) of all high-cost users had an unplanned index hospital admission, compared to $8838 / 527541(1.7 \%)$ of non-high-cost users. High-cost users had a poorer health status, longer acute length of stay (mean $7.5 \mathrm{~d}$ v. $2.9 \mathrm{~d})$ and more frequent designation as alternate level of care before discharge $(20.8 \% \mathrm{v} .1 .7 \%)$ than did non-high-cost users. Ten diagnosis codes accounted for roughly one-third of the index hospital admission costs in both cohorts. Although many predictors were similar between the cohorts, a lower risk of an index hospital admission was associated with residence in long-term care, attachment to a primary care provider and recent consultation by a geriatrician among high-cost users.

Interpretation: The high prevalence of index hospital admissions and the corresponding costs are a distinctive feature of incident older high-cost users. Improved access to specialist outpatient care, home-based social care and long-term care when required are worth further investigation.

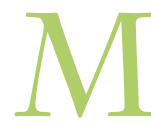
ost public health care spending is concentrated within a small group of patients. ${ }^{1}$ The top $5 \%$ most costly patients, referred to as the high-cost health care users, accounted for $61.1 \%$ of all publicly funded health care expenditures in Ontario, which amounted to $\$ 55.9$ billion in 2016/17.2,3 Older high-cost users represent $60 \%$ of the overall high-cost user population. ${ }^{2}$ Since about two-thirds of the costs among older high-cost users are accrued through hospital admissions, ${ }^{2,46}$ a detailed examination of older high-cost users admitted to hospital is warranted.

Currently, there is limited information on several key aspects of hospital admissions among older high-cost users, such as 1) the first admission, as opposed to readmission, since the first (or index) admission is the most important predictor of subsequent admissions, which, in older adults, may indicate a point where management efforts are less successful, ${ }^{7-9} 2$ ) the contribution of individual conditions to the financial burden of admission, which would help programs identify clinical drivers of the highest inpatient expenditures that are potentially divertible by managing risk factors, 3 ) outcomes of admission, such as inpatient mortality, and 4) characteristics of incident high-cost users as opposed to prevalent high-cost users, which would allow identification of the factors that influence the transition to high-cost user status. More specifically, although sociodemographic and health attributes of older high-cost users have been reported in Canada and elsewhere, ${ }^{1,10-12}$ little is

Competing interests: None declared.

This article has been peer reviewed.

Correspondence to: Sergei Muratov, muratos@mcmaster.ca

CMAJ Open 2019. DOI:10.9778/cmajo.20180185 
known about the health care of this population before they become high-cost users, especially in Canada, and how these attributes compare to those of non-high-cost users.

Given health care planners' growing concern over the escalating costs and challenges in managing high-cost users, ${ }^{13}$ a better characterization of the first unplanned hospital admission among incident older high-cost users is a timely exercise with important implications for health policies aimed at curbing health care costs or reallocating resources. The objectives of the current study were therefore to describe attributes of the first unplanned hospital admission in the year of becoming a high-cost user among incident older high-cost users and compare them to those of non-high-cost users, and to determine predictors of these admissions in the 2 cohorts.

\section{Methods}

\section{Design and population}

We conducted a retrospective population-based matched cohort study using 2 years of provincial patient data. The 2013/14 Ontario government fiscal year was considered the incident year, and the 2012/13 fiscal year was the baseline, or preincident, year.
We defined incident older high-cost users as people aged 66 years or more with annual total health care expenditures within the top 5\% threshold of all Ontarians in 2013/14 who were not in the top $5 \%$ in 2012/13. The $5 \%$ threshold is commonly used in studies of high-cost users in Canada and elsewhere. ${ }^{5,6,10,14}$ Older non-high-cost users were Ontarians with annual total health care expenditures in both 2012/13 and 2013/14 less than the top 5\% threshold. We matched the incident high-cost user cohort with non-high-cost users in a ratio of $1: 3$ according to age at cohort entry ( $\pm 1 \mathrm{mo}$ ), sex and Local Health Integration Network (health district) of patient residence. We applied the age threshold of 66 years to capture prescription numbers and costs for at least 1 year before 2013/14, as Ontario Drug Benefits eligibility begins at the age of 65 . Figure 1 presents the patient flow.

\section{Data sources}

We created the individual-level data set using health administrative databases from Ontario housed at ICES. These databases, which are subject to data quality assessments, ${ }^{15}$ contain linkable records of publicly funded health care services for the Ontario population eligible for health coverage. We derived basic demographic information from the Ontario Registered

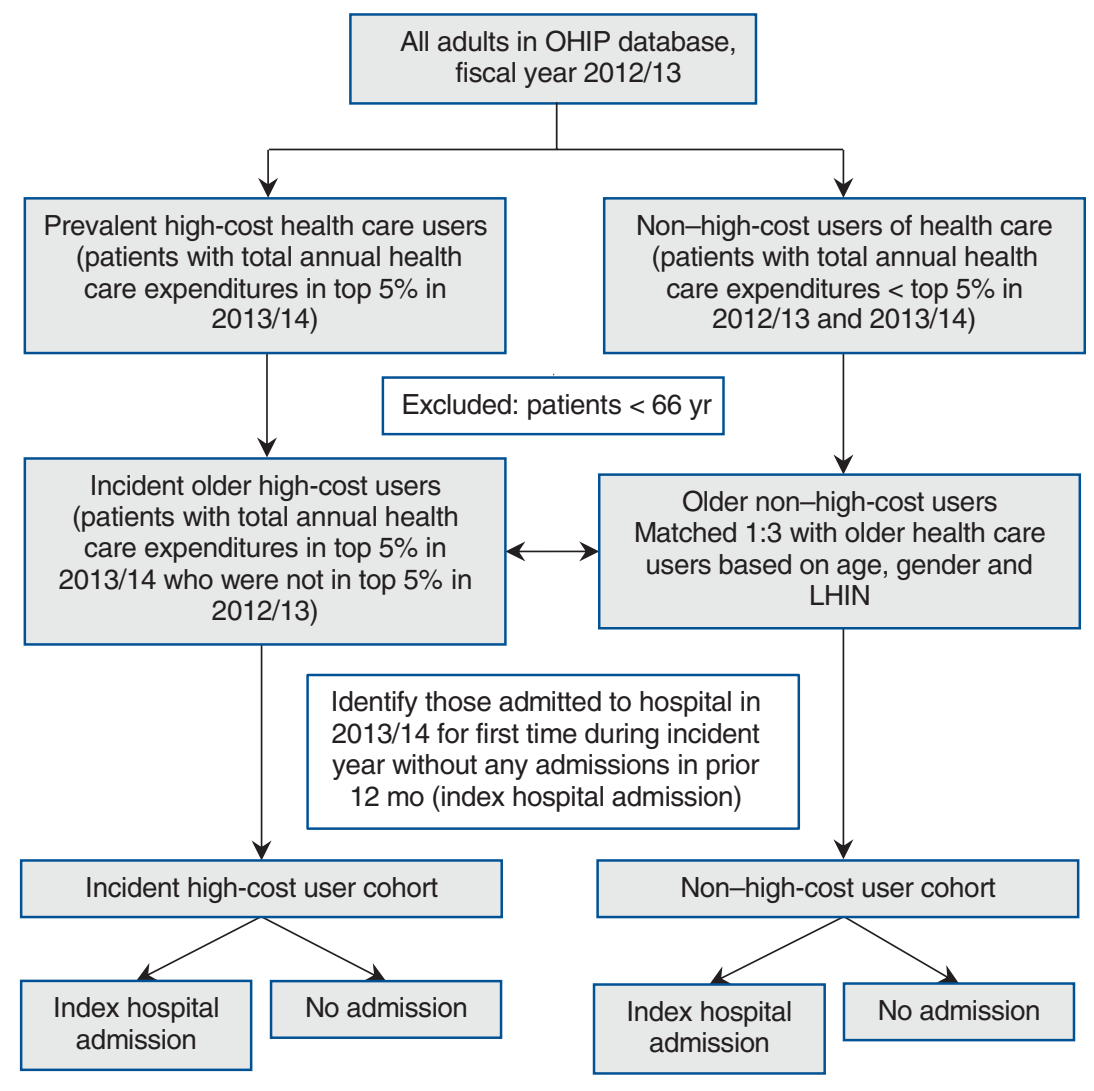

Figure 1: Flow chart showing cohort identification. Note: LHIN = Local Health Integration Network, OHIP = Ontario Health Insurance Plan. 
Persons Database. We obtained the health status and comorbidities of the study population from several sources, including the Canadian Institute for Health Information Discharge Abstract Database, National Ambulatory Care Reporting System, and ICES-derived and -validated cohorts. We measured health care characteristics using the Ontario Health Insurance Plan (physician visits), Home Care Database (home care visits), Ontario Drug Benefit Plan (number of prescriptions) and Discharge Abstract Database (admission attributes). Appendix 1 (available at www.cmajopen.ca/content/7/3/E537/ suppl/DC1) provides more detail on the data sources. We calculated health care expenditures using ICES person-level costing algorithms based on a costing methodology that links data on use of health care resources from administrative databases and costs collected by the provincial public payer. ${ }^{16}$ Costs were expressed in 2013 Canadian dollars. More details on the study design and data sources were published as a study protocol elsewhere. ${ }^{17}$

\section{Patient characteristics}

The study population was characterized by several variables, all of which can be grouped into 3 major categories. The sociodemographic status was described by age, sex, low income status, place of residence (urban v. rural) and history of recent immigration. Health status was primarily described by the number of Johns Hopkins Aggregate Diagnosis Groups that the patient was assigned. ${ }^{18}$ Also, we used Johns Hopkins Expanded Diagnosis Clusters to construct additional variables such as a history of hypertension or malignant disease to describe health status. Finally, health care characteristics in the baseline year included the number of prescriptions and health care visits and placement with a long-term facility. The variables are briefly summarized in Appendix 1.

\section{Unplanned index hospital admissions}

We defined patients with an unplanned index hospital admission, the main outcome, as people who had not been admitted to hospital for at least 12 months before their first acute inpatient hospital admission in 2013/14. The 12-month window ensured that the index hospital admission was less likely to be associated with a recent admission and therefore represents the first hospital admission event in the incident year contributing to the costs. We defined unplanned index hospital admissions as nonelective admissions, as recorded in the Discharge Abstract Database. We used the International Statistical Classification of Diseases and Related Health Problems, 10th revision, enhanced Canadian version (ICD-10-CA) diagnosis code most responsible for resource use to define the reason for each hospital admission. Each hospital admission recorded in the study consisted of the acute care portion and alternate level of care (patients who no longer require acute care but who occupy a hospital bed while awaiting placement in another health care facility $\left.{ }^{19}\right)$. We did not measure pre- and postadmission time, i.e., we did not account for time spent in the emergency department before hospital admission, or time in care at home or in other facilities after discharge from hos- pital. We summarized the acute portion of each hospital length of stay as the mean number of the days of the hospital stay. We also calculated the proportion of patients who were admitted to a teaching facility and the proportion who resided in a Local Health Integration Network different from the hospital Local Health Integration Network (Appendix 1). We calculated costs of the index hospital admission using ICD-10-CA diagnosis codes. We defined inpatient mortality as all-cause in-hospital mortality among the subset of patients who had an unplanned index hospital admission. In addition, we calculated the number of days patients were in hospital before death.

\section{Statistical analysis}

\section{Descriptive analysis}

We first compared the patient characteristics of the 2 cohorts in 2012/13 by measuring the absolute standardized difference (ASD). An ASD value of 0.1 or greater indicates a meaningful difference. ${ }^{20} \mathrm{We}$ then described the attributes of the unplanned index hospital admissions among incident highcost users versus non-high-cost users in terms of the acute portion of each hospital length of stay, ALC, discharge disposition and in-hospital death. Third, we determined the most common clinical causes of admission and their associated costs for both cohorts. We also computed the cumulative percentage of the total costs of the unplanned index hospital admissions using ICD-10-CA diagnosis codes and the average annual costs for each diagnosis.

\section{Predictive analysis}

We used logistic regression, 1 model for either cohort, to identify independent predictors of an unplanned index hospital admission. For both models, an index hospital admission event was the binary dependent variable. The list of potential predictors (independent variables) consisted of sociodemographic, health status and health care characteristics measured in 2012/13 that are described under the corresponding sections of Appendix 1. Odds ratios (ORs) and 95\% confidence intervals (CIs) were reported. We included all relevant variables in the models regardless of their statistical significance. We assessed model discrimination using the C-statistic, where a C-statistic value of 0.70 or greater indicates good discrimination. ${ }^{21} \mathrm{We}$ evaluated the model's ability to predict subgroups of patients with a differing risk of index hospital admission. ${ }^{22,23} \mathrm{We}$ validated the models by means of cross-validation ${ }^{24}$ and checked them for multicollinearity. Additional information on the statistical methods is provided in Appendices 2 and 3, available at www.cmajopen.ca/content/7/3/E537/suppl/DC1. For sensitivity analysis, we reran the models individually on the 5 most costly conditions in both cohorts, examining the effect on predictor estimates (Appendix 4, available at www.cmajopen.ca/ content/7/3/E537/suppl/DC1).

\section{Ethics approval}

This study was approved by the Hamilton Integrated Research Ethics Board. 


\section{Results}

\section{Baseline patient characteristics}

The total study population consisted of 703388 patients, of whom 175847 were incident high-cost users. The average age was 77.7 years. In both cohorts, $53.0 \%$ of patients were women. Patients resided predominantly in suburban areas (Table 1). Compared to non-high-cost users, high-cost users were sicker (mean number of Aggregate Diagnosis Groups 10.2 v. $7.9 \%$, ASD 0.54 ) and were dispensed a higher mean number of medications (8.4 v. 5.6, ASD 0.6) in the year preceding the index year, and a higher proportion visited their primary care provider $(95.6 \%$ v. $84.3 \%$, ASD 0.38$)$, received specialty care $(89.8 \%$ v. $74.2 \%$, ASD 0.41$)$ and received home care services. High-cost users were more likely than nonhigh-cost users to have a primary care provider $(97.0 \% \mathrm{v}$. 88.6\%, ASD 0.33). Almost one-third (31.8\%) of high-cost users visited an emergency department, compared to $19.3 \%$ of non-high-cost users (ASD 0.29). A higher proportion of non-high-cost users than high-cost users were recent immigrants ( $4.3 \%$ v. $2.4 \%$, ASD 0.11). The study cohorts were otherwise similar.

\section{Characteristics of unplanned index hospital admission}

Unplanned index hospital admissions accounted for $71.2 \%$ and $82.1 \%$ of index hospital admissions among high-cost users and non-high-cost users, respectively. More than half (95 375 [54.2\%]) of high-cost users had an unplanned index hospital admission, compared to 8838 non-high-cost users $(1.7 \%)$ (Table 2). Compared to non-high-cost users, highcost users had a longer hospital stay (mean acute portion of each hospital length of stay 7.5 d v. 2.9 d, ASD 0.73), were designated ALC status in higher numbers $(20.8 \%$ v. $1.7 \%$, ASD 0.64) and, once transferred to ALC, had a relatively greater number of ALC days (2.97 v. 0.06, ASD 0.32). A total of $23.0 \%$ of high-cost users were transferred to another acute care or long-term care facility, compared to $1.3 \%$ of non-high-cost users, whereas most non-high-cost users $(83.6 \%)$ were discharged home (with or without support). There was a striking difference in inpatient mortality between the cohorts: non-high-cost users were more than twice as likely as high-cost users to die in hospital $(13.9 \% \mathrm{v}$. $5.6 \%$, ASD 0.28), despite the high-cost users' longer mean acute portion of each hospital length of stay. Among those who died in hospital, non-high-cost users had a substantially shorter stay before death than high-cost users $(2.3 \mathrm{~d} \mathrm{v}$. $16.1 \mathrm{~d}$, ASD 0.97).

\section{Index hospital admission costs}

Unplanned index hospital admissions accounted for $74.4 \%$ of the costs associated with all index hospital admissions (unplanned plus elective) during the year of study among high-cost users and $81.3 \%$ of these costs among non-highcost users. The total 1-year inpatient cost associated with unplanned index hospital admissions was $\$ 1.2$ billion for highcost users and $\$ 33.1$ million for non-high-cost users. The average cost per patient associated with unplanned index hospital admissions was \$12 471 (standard deviation \$19 935) and \$3749 (standard deviation \$1290), respectively. Ten conditions accounted for roughly one-third (36.4\% among highcost users and $35.3 \%$ among non-high-cost users) of the costs (Tables 3 and 4). Acute myocardial infarction (7.8\%) was the leading most costly reason of the index hospital admission among high-cost users, whereas pneumonia (5.9\%) was the leading most costly reason of the index hospital admission among non-high-cost users. Five conditions (cerebral infarction, congestive heart failure, pneumonia, chronic obstructive pulmonary disease and ileus/intestinal obstruction) were among the 10 most costly conditions in both cohorts. The costliest conditions were also the most frequent causes of unplanned hospital admissions in both cohorts.

\section{Predictors of unplanned index hospital admission}

Overall, the direction, magnitude and significance of ORs were similar across the 2 cohorts for many of the predictors of an unplanned index hospital admission (Table 5). Predictors specific to the high-cost user cohort included having visited a geriatrician in the previous year and living at a longterm care facility. Both were associated with lower odds of an index hospital admission (OR 0.80, 95\% CI 0.76-0.86 and OR $0.29,95 \%$ CI $0.25-0.34$, respectively). Among non-highcost users, recent immigrants had lower odds of an index hospital admission (OR $0.72,95 \%$ CI $0.62-0.84$ ). In contrast to many predictors with a low magnitude of association, the home care services category "other" for high-cost users had a protective effect against an index hospital admission (OR $0.94,95 \%$ CI $0.93-0.94)$. Since this variable was constructed to include a combination of social services, respite care and case management, it was impossible to identify the impact of each of these services alone. Finally, incident high-cost users who had a primary care provider were at lower risk for an index hospital admission, whereas among non-high-cost users, attachment to a provider was associated with an increase in index hospital admissions.

\section{Interpretation}

By examining the first hospital admission during the incident year among new older high-cost users compared to non-highcost users matched on age, sex and health district in Ontario, we found that unplanned index hospital admissions were much more common among high-cost users, with more than half having an unplanned index hospital admission, compared to less than $2 \%$ of non-high-cost users. Ten conditions, many of which have known remediable risk factors for hospital admission, ${ }^{25-29}$ accounted for a large number of these admissions and one-third of their costs. Besides a greater admission rate, incident high-cost users had longer hospital stays and were frequently designated as ALC. Also, high-cost users who died in hospital had an average hospital stay of more than 2 weeks, which suggests a terminal disease stage. Finally, our findings indicate that, despite a few predictors (e.g., visits to a geriatrician or attachment to a primary care provider) that 
Table 1: Characteristics of high-cost health care users and non-high-cost users in the preincident year

\begin{tabular}{|c|c|c|c|}
\hline \multirow[b]{2}{*}{ Characteristic } & \multicolumn{2}{|c|}{ No. $(\%)$ of patients* } & \multirow[b]{2}{*}{ ASD† } \\
\hline & $\begin{array}{c}\text { High-cost users } \\
n=175847\end{array}$ & $\begin{array}{c}\text { Non-high-cost } \\
\text { users } \\
n=527541\end{array}$ & \\
\hline \multicolumn{4}{|l|}{ Sociodemographic } \\
\hline Age, yr, mean \pm SD & $77.66 \pm 7.65$ & $77.66 \pm 7.65$ & 0 \\
\hline Female sex & $93167(53.0)$ & $279501(53.0)$ & 0 \\
\hline Rural Index of Ontario score, $\ddagger$ mean \pm SD & $12.23 \pm 18.20$ & $11.81 \pm 18.18$ & 0.02 \\
\hline Low income & $31857(18.1)$ & $92566(17.5)$ & 0.01 \\
\hline Recent immigrant (< 15 yr in Canada) & $4211(2.4)$ & $22577(4.3)$ & 0.11 \\
\hline \multicolumn{4}{|l|}{ Health status } \\
\hline No. of Adjusted Diagnostic Groups, mean \pm SD & $10.22 \pm 4.00$ & $7.93 \pm 4.47$ & 0.54 \\
\hline Hypertension§ & $110733(63.0)$ & $282867(53.6)$ & 0.19 \\
\hline Congestive heart failure & $25203(14.3)$ & $36877(7.0)$ & 0.24 \\
\hline Chronic obstructive pulmonary diseaseף & $48761(27.7)$ & $96513(18.3)$ & 0.23 \\
\hline Diabetesף & $62031(35.3)$ & $138794(26.3)$ & 0.20 \\
\hline Myocardial infarction & $12894(7.3)$ & $24024(4.6)$ & 0.12 \\
\hline Rheumatoid arthritis & 5607 (3.2) & $9334(1.8)$ & 0.09 \\
\hline Malignant disease§ & 56869 (32.3) & $123932(23.5)$ & 0.20 \\
\hline Mental health condition§ & $67468(38.4)$ & $144377(27.4)$ & 0.24 \\
\hline \multicolumn{4}{|l|}{ Health care use $e^{\star \star}$} \\
\hline Long-term care facility & $835(0.5)$ & $316(0.1)$ & 0.08 \\
\hline \multicolumn{4}{|l|}{ Primary care provider } \\
\hline Fee for service & $16947(9.6)$ & $45751(8.7)$ & 0.03 \\
\hline Capitation & $48717(27.7)$ & $133915(25.4)$ & 0.05 \\
\hline Enhanced fee for service†† & $51665(29.4)$ & $143940(27.3)$ & 0.05 \\
\hline Family Health Team & $51178(29.1)$ & $137516(26.1)$ & 0.07 \\
\hline Otherł & $2149(1.2)$ & $6249(1.2)$ & 0 \\
\hline None & $5191(3.0)$ & $60170(11.4)$ & 0.33 \\
\hline No. of medications, mean \pm SD & $8.44 \pm 4.96$ & $5.61 \pm 4.47$ & 0.60 \\
\hline Emergency department visits & $55986(31.8)$ & $101896(19.3)$ & 0.29 \\
\hline No. of emergency department visits, mean \pm SD & $0.56 \pm 1.13$ & $0.30 \pm 0.80$ & 0.26 \\
\hline Visits to general practitioner & $168090(95.6)$ & $444614(84.3)$ & 0.38 \\
\hline No. of visits to general practitioner, mean \pm SD & $8.03 \pm 6.79$ & $5.63 \pm 5.58$ & 0.39 \\
\hline Visits to specialist & $157876(89.8)$ & $391557(74.2)$ & 0.41 \\
\hline No. of visits to specialist, mean \pm SD & $7.40 \pm 6.65$ & $4.43 \pm 5.13$ & 0.50 \\
\hline Visits to geriatrician & $4974(2.8)$ & $5935(1.1)$ & 0.12 \\
\hline \multicolumn{4}{|l|}{ Home care visits } \\
\hline Nursing & $7223(4.1)$ & $7385(1.4)$ & 0.17 \\
\hline No. of visits by nursing, mean $\pm S D$ & $0.54 \pm 4.03$ & $0.16 \pm 2.00$ & 0.12 \\
\hline Personal support & $13807(7.8)$ & $10612(2.0)$ & 0.27 \\
\hline No. of visits by personal support, mean \pm SD & $6.44 \pm 30.59$ & $1.46 \pm 13.53$ & 0.21 \\
\hline Allied health care & $9259(5.3)$ & $7982(1.5)$ & 0.21 \\
\hline No. of visit by allied health care, mean \pm SD & $0.18 \pm 0.99$ & $0.05 \pm 0.52$ & 0.17 \\
\hline Other§§ & $27638(15.7)$ & $25965(4.9)$ & 0.36 \\
\hline No. of visits by other, mean $\pm S D$ & $0.58 \pm 2.30$ & $0.14 \pm 0.96$ & 0.25 \\
\hline \multicolumn{4}{|c|}{ 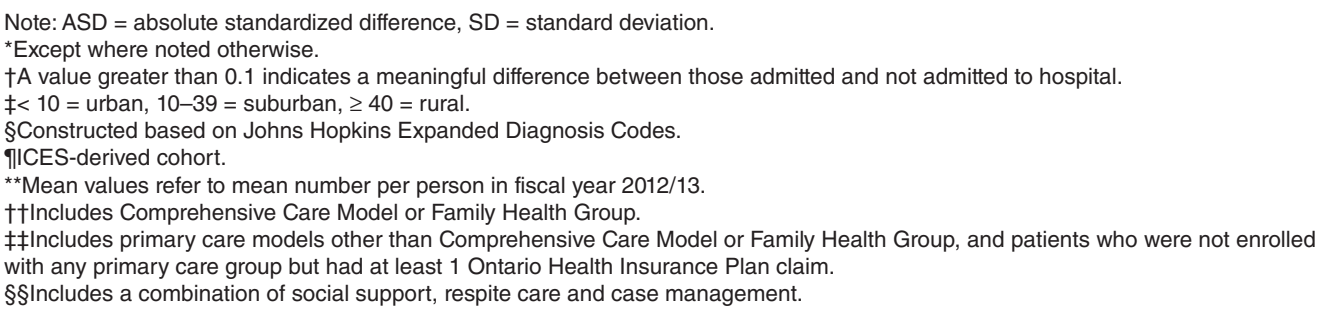 } \\
\hline
\end{tabular}




\begin{tabular}{|c|c|c|c|}
\hline \multirow[b]{2}{*}{ Characteristic } & \multicolumn{2}{|c|}{$\begin{array}{l}\text { No. }(\%) \text { of total patients with } \\
\text { index hospital admission* }\end{array}$} & \multirow[b]{2}{*}{ ASD† } \\
\hline & High-cost users & $\begin{array}{l}\text { Non-high- } \\
\text { cost users }\end{array}$ & \\
\hline $\begin{array}{l}\text { No. of patients with index hospital admission } \\
\text { (\% of total population) }\end{array}$ & $133895(76.1)$ & $10770(2.0)$ & - \\
\hline Unplanned index hospital admission & $95375(71.2)$ & $8838(82.1)$ & - \\
\hline Acute length of stay, $\mathrm{d}$, mean $\pm \mathrm{SD}$ & $7.52 \pm 8.71$ & $2.91 \pm 2.16$ & 0.73 \\
\hline Alternate level of care status & $19915(20.9)$ & $149(1.7)$ & 0.64 \\
\hline $\begin{array}{l}\text { Days spent in alternate level of care, mean } \\
\pm \mathrm{SD} \dagger\end{array}$ & $2.97 \pm 12.72$ & $0.06 \pm 0.72$ & 0.32 \\
\hline \multicolumn{4}{|l|}{ Discharge disposition } \\
\hline Inpatient hospital care & $6281(6.6)$ & $47(0.5)$ & 0.33 \\
\hline Long-term or continuing care facility & $15636(16.4)$ & $70(0.8)$ & 0.58 \\
\hline Home with support $\ddagger$ & $23832(25.0)$ & $1097(12.4)$ & 0.33 \\
\hline Home & $43000(45.1)$ & $6293(71.2)$ & 0.55 \\
\hline Death before discharge & $5378(5.6)$ & 1226 (13.9) & 0.25 \\
\hline Other§ & $1248(1.3)$ & $105(1.2)$ & 0.02 \\
\hline $\begin{array}{l}\text { Days spent in hospital before death, mean } \\
\pm \text { SD }\end{array}$ & $16.12 \pm 20.09$ & $2.32 \pm 1.85$ & 0.97 \\
\hline Admitted to teaching care facility & $25609(26.8)$ & $2097(23.7)$ & 0.07 \\
\hline $\begin{array}{l}\text { Admitted to acute care facility outside health } \\
\text { district }\end{array}$ & $10392(10.9)$ & 770 (8.7) & 0.07 \\
\hline \multicolumn{4}{|c|}{$\begin{array}{l}\text { Note: ASD = absolute standardized difference, } \mathrm{SD}=\text { standard deviation. } \\
\text { *Except where noted otherwise. } \\
\text { †A value greater than } 0.1 \text { indicates a meaningful difference between the cohorts. } \\
\text { †Support options included retirement lodge, attendant care, home care, Meals on Wheels, homemaking and } \\
\text { supportive housing. } \\
\text { §lncludes transfer to other ambulatory care, palliative care/hospice, addiction treatment centre or jail, and those } \\
\text { who signed out against medical advice. }\end{array}$} \\
\hline
\end{tabular}

were unique to either cohort, there were many similarities in baseline predictors of the first unplanned admission between the 2 cohorts, including health care received before the incident year. The fact that incident high-cost users who had a primary care provider were at lower risk for hospital admission whereas among non-high-cost users, attachment to a provider was associated with an increase in index hospital admissions may reflect the existence of subgroups of "orphan" patients who differ based on severity of illness, personality type, social circumstance or, among high-cost users, access to primary care. ${ }^{30}$

Any comparison of our results with other studies is challenging owing to methodological heterogeneity such as the lack of differentiation between the category of admission (unplanned v. elective), inclusion of readmissions or use of a different high-cost user threshold (e.g., top 1\%). However, our results are consistent with previous research in several aspects. First, our list of the most frequent and most costly disease codes is overall in line with prior limited studies on older high-cost users from Canada and elsewhere that examined the financial contribution of individual conditions: cardiovascular, orthopedic and infectious diseases are predomi- nant reasons for admissions. ${ }^{6,31}$ Furthermore, the risk of unplanned hospital admissions among community-dwelling older adults was examined by means of several models from various jurisdictions. ${ }^{9}$ Similar to our results, older age, male sex, visits to the emergency department and prevalent chronic conditions were associated with higher odds of admission. Our findings support earlier reports of the "healthy immigrant effect:" 32 recent immigrants were less likely than those who had been in Canada longer to become high-cost users or have an index hospital admission. In contrast to previous studies of the general older population that suggested residence at a nursing home as a predictor of future admission, especially for fracture, ${ }^{33,34}$ in the current study, living in a long-term care facility was associated with lower risk of unplanned index hospital admissions among incident high-cost users.

\section{Strengths and limitations}

Key strengths of this study include its population-based matched design and examination of poorly studied aspects of the population of older high-cost users in the Canadian context. Our study also has limitations. The discriminatory 


\begin{tabular}{|c|c|c|c|c|c|}
\hline Condition & $\begin{array}{l}\text { ICD-10-CA } \\
\text { code* }^{*}\end{array}$ & Inpatient cost, \$ & $\begin{array}{c}\text { No. }(\%) \text { of } \\
\text { patients } \\
n=95375\end{array}$ & $\begin{array}{l}\text { Average } \\
\text { cost, \$ }\end{array}$ & $\begin{array}{l}\text { Cumulative } \\
\text { to total } \\
\text { unplanned } \\
\text { costs, \% }\end{array}$ \\
\hline Acute myocardial infarction & 121 & 92924331.27 & $6045(6.3)$ & 15372.10 & 7.8 \\
\hline Fracture of femur & S72 & 84898511.82 & $5181(5.4)$ & 16386.51 & 15.0 \\
\hline Cerebral infarction & 163 & 54321115.26 & $3912(4.1)$ & 13885.77 & 19.5 \\
\hline Heart failure & 150 & 41778511.43 & $4069(4.3)$ & 10267.51 & 23.0 \\
\hline $\begin{array}{l}\text { Chronic obstructive } \\
\text { pulmonary disease }\end{array}$ & J44 & 37347675.22 & $4184(4.4)$ & 8926.31 & 26.2 \\
\hline Septicemia & A41 & 31204568.40 & $1487(1.6)$ & 20984.91 & 28.8 \\
\hline Pneumonia & J18 & 25734867.64 & $2811(2.9)$ & 9155.06 & 31.0 \\
\hline $\begin{array}{l}\text { Chronic ischemic heart } \\
\text { disease }\end{array}$ & 125 & 25625722.16 & $1352(1.4)$ & 18953.94 & 33.1 \\
\hline $\begin{array}{l}\text { Delirium, not induced by } \\
\text { alcohol and other } \\
\text { psychoactive substances }\end{array}$ & F05 & 20132341.32 & $1305(1.4)$ & 15427.08 & 34.8 \\
\hline $\begin{array}{l}\text { Paralytic ileus and intestinal } \\
\text { obstruction without hernia }\end{array}$ & K56 & 19169068.91 & $1501(1.6)$ & 12770.87 & 36.4 \\
\hline
\end{tabular}

\section{Table 4: Ten most expensive conditions for non-high-cost users with unplanned index hospital admissions}

\begin{tabular}{|c|c|c|c|c|c|}
\hline Condition & $\begin{array}{l}\text { ICD-10-CA } \\
\text { code* }\end{array}$ & Inpatient cost, \$ & $\begin{array}{c}\text { No. }(\%) \text { of } \\
\text { patients } \\
n=8838\end{array}$ & $\begin{array}{l}\text { Average } \\
\text { cost, \$ }\end{array}$ & $\begin{array}{c}\text { Cumulative } \\
\text { to total } \\
\text { unplanned } \\
\text { costs, \% }\end{array}$ \\
\hline Pneumonia & J18 & 1970228.65 & $439(5.0)$ & 4487.99 & 5.9 \\
\hline $\begin{array}{l}\text { Chronic obstructive } \\
\text { pulmonary disease }\end{array}$ & J44 & 1448358.06 & $304(3.4)$ & 4764.34 & 10.3 \\
\hline Syncope and collapse & R55 & 1337333.96 & $432(4.9)$ & 3095.68 & 14.4 \\
\hline Atrial fibrillation and flutter & 148 & 1120050.76 & $316(3.6)$ & 3544.46 & 17.7 \\
\hline Disorders of urinary system & N39 & 1115864.19 & $267(3.0)$ & 4179.27 & 21.1 \\
\hline Heart failure & 150 & 1114152.33 & $235(2.7)$ & 4741.07 & 24.5 \\
\hline Pain in throat and chest & R07 & 1040653.40 & $373(4.2)$ & 2789.96 & 27.6 \\
\hline $\begin{array}{l}\text { Paralytic ileus and intestinal } \\
\text { obstruction }\end{array}$ & K56 & 887672.60 & $266(3.0)$ & 3337.12 & 30.3 \\
\hline Cerebral infarction & 163 & 834442.33 & $153(1.7)$ & 5453.87 & 32.8 \\
\hline Other medical care & Z51 & 818227.58 & $266(3.0)$ & 3076.04 & 35.3 \\
\hline
\end{tabular}

power of the models was only fair, although the C-statistic values were close to those in several previously reported risk prediction models in the general older population. ${ }^{9}$ Running the models with more homogeneous subgroups of patients (e.g., chronic obstructive pulmonary disease, heart failure) improved model discrimination (e.g., C-statistic > 0.7), especially for high-cost users (Appendix 4), and these results were consistent with the main analyses. Furthermore, some 


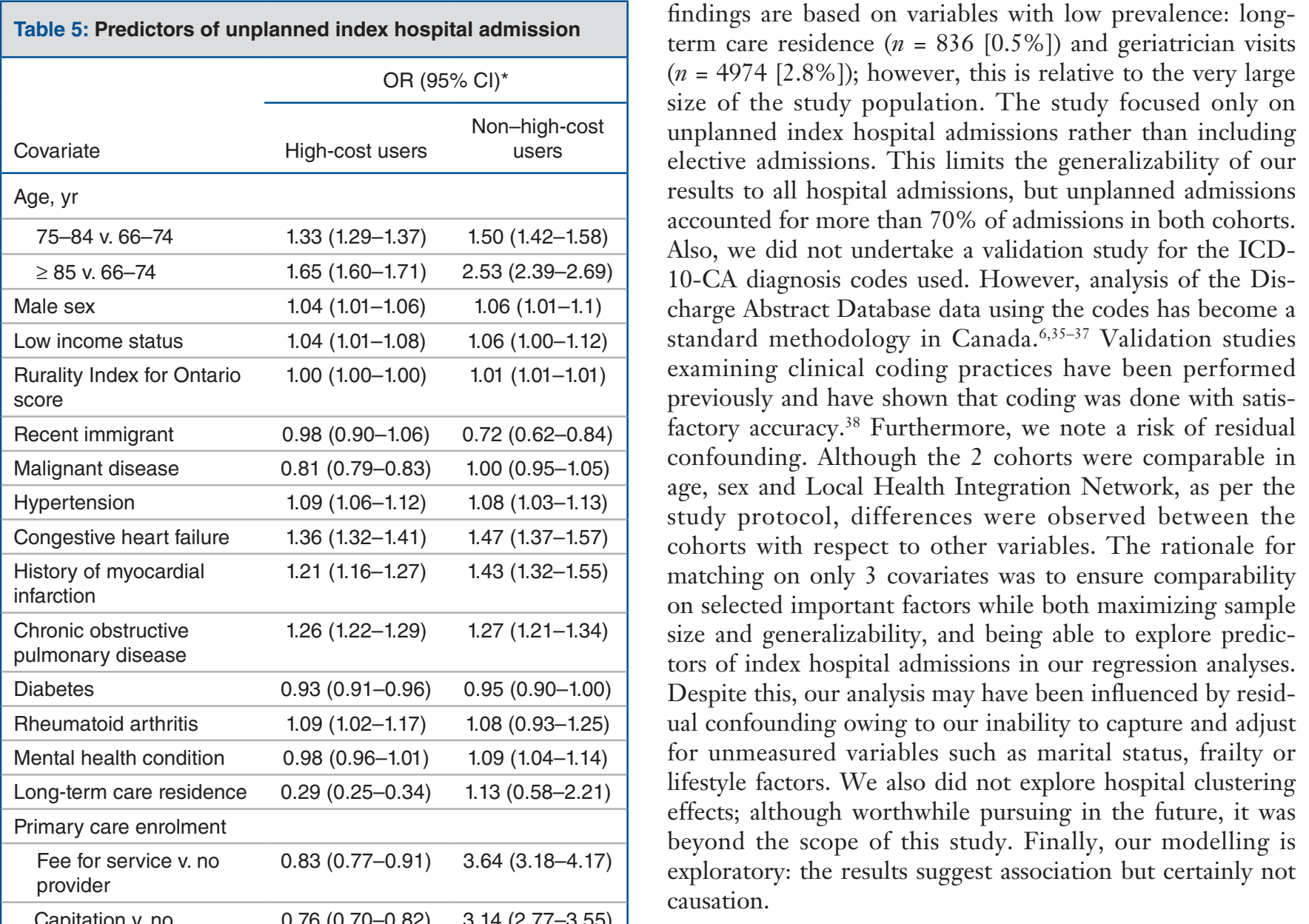

\begin{tabular}{|c|c|c|}
\hline $\begin{array}{l}\text { Capitation v. no } \\
\text { provider }\end{array}$ & $0.76(0.70-0.82)$ & $3.14(2.77-3.55)$ \\
\hline $\begin{array}{l}\text { Enhanced fee for } \\
\text { service v. no provider }\end{array}$ & $0.78(0.72-0.84)$ & 2.99 (2.64-3.39) \\
\hline $\begin{array}{l}\text { Family Health Team } \\
\text { v. no provider }\end{array}$ & $0.79(0.73-0.85)$ & $3.65(3.23-4.13)$ \\
\hline Other v. no provider & $0.89(0.78-1.03)$ & $4.75(3.91-5.77)$ \\
\hline Prescription drugs & $0.99(0.98-0.99)$ & $1.01(1.01-1.02)$ \\
\hline $\begin{array}{l}\text { Emergency department } \\
\text { visits }\end{array}$ & $1.06(1.05-1.08)$ & $1.16(1.14-1.18)$ \\
\hline $\begin{array}{l}\text { Visits to general } \\
\text { practitioner }\end{array}$ & $1.00(0.99-1.00)$ & $1.00(0.99-1.00)$ \\
\hline Visits to specialist & $0.95(0.95-0.95)$ & $0.99(0.99-1.00)$ \\
\hline Visits to geriatrician & $0.80(0.76-0.86)$ & $1.06(0.89-1.26)$ \\
\hline \multicolumn{3}{|l|}{ Home care visits } \\
\hline Nursing & $0.99(0.99-1.00)$ & $1.01(1.00-1.01)$ \\
\hline Personal support & $1.00(1.00-1.00)$ & $1.00(0.99-1.00)$ \\
\hline Allied health care & $1.01(1.00-1.02)$ & $1.01(0.98-1.05)$ \\
\hline Other & $0.94(0.93-0.94)$ & $1.02(1.01-1.04)$ \\
\hline C-statistic & 0.65 & 0.67 \\
\hline $\begin{array}{l}\text { C-statistic } \\
\text { (cross-validated) }\end{array}$ & 0.65 & 0.67 \\
\hline
\end{tabular}

\section{Conclusion}

The high prevalence of unplanned index hospital admissions and the corresponding costs driven partly by longer lengths of stay for acute care and more ALC are a distinctive feature of older incident high-cost users. The effect of improved access to specialist outpatient care, home-based social care and long-term care when required in avoiding index hospital admissions warrants further research, especially among the most costly conditions.

\section{References}

1. Wammes JJG, van der Wees PJ, Tanke MAC, et al. Systematic review of highcost patients' characteristics and healthcare utilisation. BMF Open 2018;8: e023113.

2. Rais S, Nazerian A, Ardal S, et al. High-cost users of Ontario's healthcare services. Healthc Policy 2013;9:44-51.

3. Expenditure estimates for the Ministry of Health and Long-Term Care (2018www.ontario.ca/page/expenditure-estimates-ministry-health-and-long-term-care -2018-19 (accessed 2019 Mar. 26).

4. Wodchis WP, Austin P, Newman A, et al. The concentration of health care spending: little ado (yet) about much (money). Canadian Association for Health Services and Policy Research (CASHPR) Conference 2012; 2012 May 29-31; Montréal. Toronto: Institute for Clinical Evaluative Sciences; 2012. Available: www.cahspr.ca/web/uploads/presentations/C6.1_Walter_P._Wodchis. pdf (accessed 2015 Oct. 1). Aff (Millwood) 2007;26:808-16.

6. Wodchis WP, Austin PC, Henry DA. A 3-year study of high-cost users of health care. CMA7 2016;188:182-8. 19). Government of Ontario; 2018 Apr. 23, updated 2019 Mar. 1. Available:

5. Riley GF. Long-term trends in the concentration of Medicare spending. Health 
7. Peikes D, Chen A, Schore J, et al. Effects of care coordination on hospitalization, quality of care, and health care expenditures among Medicare beneficiaries: 15 randomized trials. FAMA 2009;301:603-18.

8. Dattalo M, Nothelle S, Chapman EN. Targeting enhanced services toward high-cost, high-need Medicare patients. In: New directions in geriatric medicine: concepts, trends, and evidence-based practice. Cham (Switzerland): Springer International Publishing; 2016:13-30.

9. Wallace E, Stuart E, Vaughan N, et al. Risk prediction models to predict emergency hospital admission in community-dwelling adults: a systematic review. Med Care 2014;52:751-65.

10. Holtz-Eakin D. High-cost Medicare beneficiaries. Washington: Congressional Budget Office; 2005. Available: www.cbo.gov/publication/16487 (accessed 2019 Jan. 16).

11. Sinha SK. Why the elderly could bankrupt Canada and how demographic imperatives will force the redesign of acute care service delivery. Healtbc Pap 2011;11:46-51, discussion 86-91.

12. Clough JD, Riley GF, Cohen M, et al. Patterns of care for clinically distinct segments of high cost Medicare beneficiaries. Healthc (Amst) 2016;4:160-5.

13. Lee JY, Muratov S, Tarride JE, et al. Managing high-cost healthcare users: the international search for effective evidence-supported strategies. $7 \mathrm{Am}$ Geriatr Soc 2018;66:1002-8.

14. Guilcher SJ, Bronskill SE, Guan J, et al. Who are the high-cost users? A method for person-centred attribution of health care spending. PLoS One 2016; 11:e0149179.

15. Iron K, Manuel DG. Quality assessment of administrative data (QuAAD): an opportunity for enhancing Ontario's bealth data - ICES investigative report. Toronto: ICES; 2007.

16. Wodchis WP, Bushmeneva K, Nikitovic M, et al. Guidelines on person-level costing using administrative databases in Ontario. Vol 1 of Working paper series. Toronto: Health System Performance Research Network; 2013.

17. Muratov S, Lee J, Holbrook A, et al. Senior high-cost healthcare users' resource utilization and outcomes: a protocol of a retrospective matched cohort study in Canada. BMF Open 2017;7:e018488.

18. ACG System version 10.0 technical reference guide. Baltimore: Department of Health Policy and Management, Bloomberg School of Public Health, Johns Hopkins University; 2013.

19. Sutherland JM, Crump RT. Alternative level of care: Canada's hospital beds, the evidence and options. Healthc Policy 2013;9:26-34

20. Mamdani M, Sykora K, Li P, et al. Reader's guide to critical appraisal of cohort studies: 2. Assessing potential for confounding. BM7 2005;330:960-2.

21. Hosmer DW, Lemeshow S. Applied logistic regression. 2nd ed. New York: John Wiley \& Sons; 2000.

22. Kramer AA, Zimmerman JE. Assessing the calibration of mortality benchmarks in critical care: the Hosmer-Lemeshow test revisited. Crit Care Med 2007;35:2052-6.

23. Pocock SJ, Wang D, Pfeffer MA, et al. Predictors of mortality and morbidity in patients with chronic heart failure. Eur Heart 7 2006;27:65-75.

24. Usage note 39724: ROC analysis using validation data and cross validation. Cary (NC): SAS Institute; 2010 May 21, modified 2015 July 15. Available: http://support.sas.com/kb/39/724.html (accessed 2019 Feb. 18).

25. An SJ, Kim TJ, Yoon BW. Epidemiology, risk factors, and clinical features of intracerebral hemorrhage: an update. 7 Stroke 2017;19:3-10.

26. Del Gobbo LC, Kalantarian S, Imamura F, et al. Contribution of major lifestyle risk factors for incident heart failure in older adults: the Cardiovascular Health Study. FACC Heart Fail 2015;3:520-8.

27. Lim JS, Kwon HM. Risk of "silent stroke" in patients older than 60 years: risk assessment and clinical perspectives. Clin Interv Aging 2010;5:239-51.

28. Woolf AD, Åkesson K. Preventing fractures in elderly people [published erratum in BM7 2003;327:663]. BM7 2003;327:89-95.

29. Yusuf S, Hawken S, Ounpuu S, et al.; INTERHEART Study Investigators. Effect of potentially modifiable risk factors associated with myocardial infarction in 52 countries (the INTERHEART study): case-control study. Lancet 2004;364:937-52.

30. Hay C, Pacey M, Bains N, et al. Understanding the unattached population in Ontario: evidence from the Primary Care Access Survey (PCAS). Healthc Policy 2010;6:33-47.

31. Joynt KE, Gawande AA, Orav EJ, et al. Contribution of preventable acute care spending to total spending for high-cost Medicare patients. $7 A M A$ 2013;309: 2572-8.

32. Vang ZM, Sigouin J, Flenon A, et al. Are immigrants healthier than native-born Canadians? A systematic review of the healthy immigrant effect in Canada. Ethn Health 2017;22:209-41.

33. Graverholt B, Riise T, Jamtvedt G, et al. Acute hospital admissions among nursing home residents: a population-based observational study. BMC Health Serv Res 2011;11:126.
34. Ronald LA, McGregor MJ, McGrail KM, et al. Hospitalization rates of nursing home residents and community-dwelling seniors in British Columbia. Can 7 Aging 2008;27:109-15.

35. Walker JD, Teare GF, Hogan DB, et al. Identifying potentially avoidable hospital admissions from Canadian long-term care facilities. Med Care 2009;4: 250-4.

36. Gruneir A, Bell CM, Bronskill SE, et al. Frequency and pattern of emergency department visits by long-term care residents - a population-based study. 7 Am Geriatr Soc 2010;58:510-7.

37. Hensel JM, Taylor VH, Fung K, et al. Acute care use for ambulatory caresensitive conditions in high-cost users of medical care with mental illness and addictions. Can 7 Psychiatry 2018 Jan. 1:706743717752880. doi: 10.1177/ 0706743717752880 . [Epub ahead of print].

38. Juurlink D, Preyra C, Croxford R, et al. Canadian Institute for Health Information Discharge Abstract Database: a validation study. Toronto: ICES; 2006. Available: www.ices.on.ca/ /media/Files/Atlases-Reports/2006/CIHI-DAD-a -validation-study/Full\%20report.ashx (accessed 2019 Mar. 7).

Affiliations: Department of Health Research Methods, Evidence, and Impact (Muratov, Lee, Holbrook, Mbuagbaw, Tarride) and Divisions of Geriatric Medicine (Lee) and Clinical Pharmacology and Toxicology (Holbrook), Department of Medicine, McMaster University, Hamilton, Ont.; ICES (Paterson, Gomes, Khuu, Pequeno), Toronto, Ont.; Département de médecine sociale et préventive (Guertin), Faculté de médecine, and Centre de recherche du Centre hospitalier universitaire de Québec (Guertin), Axe Santé des populations et pratiques optimales en santé, Université Laval, Québec, Que.; Li Ka Shing Knowledge Institute (Gomes), St. Michael's Hospital, Toronto, Ont.; Centre for Health Economics and Policy Analysis (Tarride) and Department of Family Medicine (Paterson), McMaster University, Hamilton, Ont.

Contributors: Sergei Muratov, Jean-Eric Tarride, Anne Holbrook, Justin Lee, Michael Paterson, Tara Gomes and Wayne Khuu conceptualized the study. Michael Paterson, Wayne Khuu, Priscila Pequeno and Tara Gomes created the data set. Sergei Muratov analyzed the data, with support from Jean-Eric Tarride, Priscila Pequeno, Jason Guertin and Lawrence Mbuagbaw. Sergei Muratov drafted the manuscript. All of the authors contributed to the study design, critically revised the manuscript for important intellectual content, approved the version to be published and agreed to be accountable for all aspects of the work.

Funding: This work was supported by in-kind support from the Ontario Drug Policy Research Network (ODPRN) and by personnel awards from the Canadian Institutes of Health Research (CIHR) Drug Safety and Effectiveness Cross-Disciplinary Training Program, the Program for Assessment of Technology in Health, The Research Institute of St. Joe's Hamilton, St. Joseph's Healthcare Hamilton and an Ontario Graduate Scholarship. The work was also supported by ICES, an independent research institute funded by the Ontario Ministry of Health and LongTerm Care (MOHLTC). The ODPRN is funded by grants from the Ontario MOHLTC and the Ontario Strategy for Patient-Oriented Research Support Unit, which is supported by CIHR and the Province of Ontario.

Disclaimer: Parts of this material are based on data and information compiled and provided by the Canadian Institute for Health Information (CIHI) and Immigration, Refugees and Citizenship Canada (IRCC). However, the analyses, conclusions, opinions and statements expressed herein are those of the authors and not necessarily those of CIHI or IRCC. The opinions, results and conclusions reported in this article are those of the authors and are independent from the funding sources. No endorsement by ICES or the Ontario MOHLTC is intended or should be inferred.

Supplemental information: For reviewer comments and the original submission of this manuscript, please see www.cmajopen.ca/content/7/3/ E537/suppl/DC1. 